\title{
Collisions with overhead wires as a cause of mortality in Mute Swans Cygnus olor
}

\author{
C.M. PERRINS and J. SEARS
}

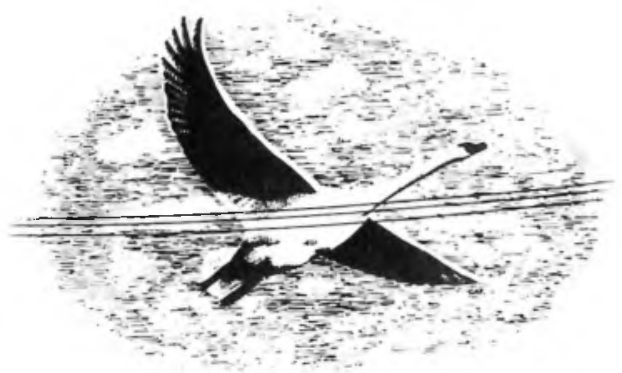

The ringing recoveries of Mute Swans held by the British Trust for Ornithology were analysed for information on deaths from collisions with overhead wires. Of reported deaths, some $22 \%$ die from such a cause. This is compared with the likely actual percentage, allowing for the fact that only a proportion of dead swans are reported and that birds dying from collisions with overhead wires are more likely to be found than are birds dying from other causes. The annual patterns of deaths from collisions with overhead cables are examined in relation to the age classes of the swans involved. Not surprisingly, fewer birds die from this cause during the summer especially during those months when the birds are in moult. At other times of year, the pattern varies with the age of the bird.

Mute Swans Cygnus olor are strong fliers, but usually require long stretches of water for take-off and landing, and cannot easily manoeuvre around objects while in flight. As a result, flying accidents are a significant source of mortality; the most common cause of these accidents is flying into overhead wires. These are often strung across rivers and are probably not easily seen by the swans in time for them to take avoiding action; this is likely to be especially true when they are flying in conditions of poor visibility such as mist or in the dark.

In this paper, we examine the frequency of flying accidents in relation to time of year and age of bird. We also look at the pattern of flying accidents and try to deduce something of the activity patterns of the swans from them. In addition we examine information on the lead levels of birds which are killed by flying into overhead wires.

The paper is based on the recoveries of ringed birds supplied by the British Trust for Omithology (BTO). Only birds which have been reported dead are used in this analysis. When a dead bird is found and reported by a member of the public, the cause of death may also be given; a cause is given in only about half the reports. In some cases, one cannot be confident that the given cause of death was the real one. For example, in the case of reports of birds being killed by foxes, one cannot be absolutely certain that the bird had actually been killed by a fox; it might equally have died from another cause and been eaten by a fox afterwards. However, when a swan flies into an overhead wire and is killed, this is usually fairly obvious and is probably usually accurately recorded. In the sample analysed here, 2409 of $11,105(21.7 \%)$ swans reported dead between 1958 and 1988, were reported as having died from flying into wires.

It is perhaps necessary to define what we mean by wire. Swans may fly into all sorts of overhead obstacles from buildings to telephone wires. The vast majority of these accidents occur when they fly into overhead electricity wires; these vary from the very large cables of the National Grid to the smaller, more local conductors and even occasionally telephone wires (though there are few of these available in most areas). Members of the public who report ringing recoveries do not distinguish between these different sorts of wires, but merely report the bird as having flown into wires. Our analysis is based on those birds coded in the Euring Code as " 43 ", collisions with a thin man-made structure. The very large majority of these relate to some form of electricity wires, but a few may not. Conversely, many birds are reported without a cause of death being given and we cannot exclude the possibility that some of these also died from flying into wires.

In the first analyses, we use all recoveries of swans found dead. Later, where we look in more detail at flying mortality, we use only those birds which were ringed as cygnets (i.e. were of known age) and were recovered dead within the first seven years of life (the samples become small after that age). In this second data set, a few recoveries of birds which died from rather unu- 


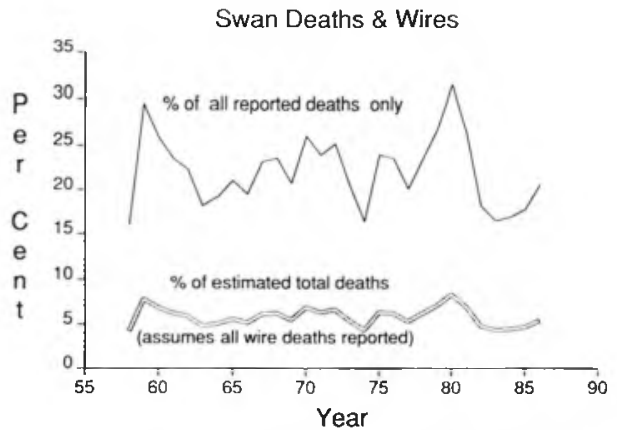

Figure 1. The proportion of all reported deaths of ringed Mute Swans ascribed to flying into overhead wires, plotted against time. The upper line shows that actual percentage of reported deaths due to such collisions, the lower line shows an estimate based on the assumption that all birds which die and are not reported did not die from colliding with wires - see text for explanation.

sual causes, such as killed by car or train, were eliminated, leaving a sample of 4557 birds from which 1101 (24.2\%) died from flying into wires.

A problem arises in plotting the number of deaths at any time of year. Cygnets can be identified as such throughout their first year of life and birds are ringed throughout this period; by no means all cygnets have been ringed by the autumn. Hence the number of cygnets which are "at risk" increases due to more birds being ringed and decreases as a result of birds dying. Perrins (1991) has estimated the numbers of ringed cygnets which are alive - and hence "at risk" of being recovered - in each month of the year; this was done by cumulatively adding the totals ringed in each month less an estimate of the numbers dying each month. The thicker lines, marked "Adjusted" in Figures 3 and 4, take account of these changes and give a truer indication of the seasonal variation of mortality than do the unadjusted numbers. Similar adjustments have not been made

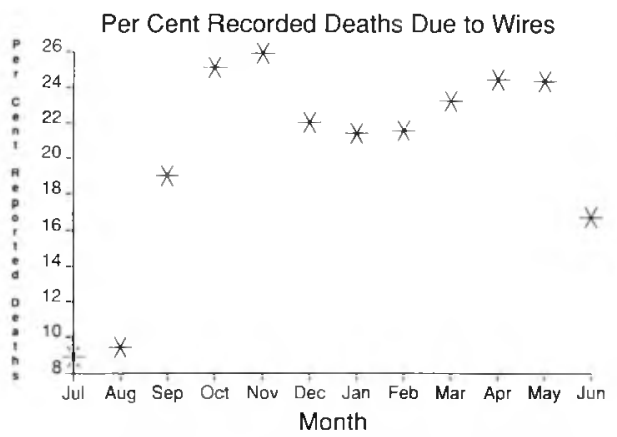

Figure 2. The percentage of reported Mute Swan deaths due to collisions with overhead wires, plotted against month of death. after the birds reach the age of four since the differences are by then negligible.

In the analysis of lead levels in Mute Swans involved in flying accidents, we use the results of tissue assays from birds which have died in our intensive study area which is the Thames from the Gloucestershire border down to Richmond, its tributaries the Windrush, Cherwell and Thame and gravel pits adjacent to these (Sears 1988).

\section{Results}

a) Proportion of swans dying from collisions with overhead wires

Figure 1 (upper line) is based on the 11,105 recoveries of dead swans during the period 1958-88 and shows the proportion of Mute Swans reported dead which were reported to have died as a result of flying into overhead wires. The percentage does not seem to have changed with time. Overall, $21.7 \%$ of the dead swans were reported to have flown into wires. Unfortunately, this is unlikely to be a reliable estimate of wires as a source of swan mortality because birds which fly into wires are more likely to be found and recorded than are birds dying from many other causes. For one thing, any bird that causes a power failure is likely to be found when a repair engineer comes out to find the fault. As a result, the frequency of mortality due to flying into overhead wires is likely to be over-estimated in this analysis.

The lower line in Figure 1 is an attempt to produce a figure which is close to the minimum possible death-rate from flying into wires. Only about $26.5 \%$ of all ringed Mute Swans which die are reported to the BTO (Perrins 1991). Hence, for every bird that is reported dead, 3.77 (100/ 26.5) birds have actually died. If one makes the (unlikely) assumption that all wire deaths are

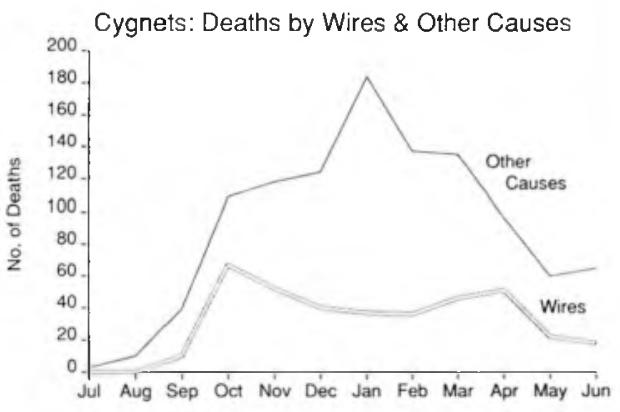

Figure 3. The monthly patterns of deaths of Mute Swans dying from flying into wires and those dying from all other causes. 
reported and therefore that all unreported deaths are due to other causes, then mortality due to flying into overhead wires would be as shown in the lower line in Figure 1 (or, overall, some $5.9 \%$ ).

We know of no objective way to decide where, between these two estimates, the true figure lies. The upper line, as mentioned, is probably too high. Equally however, the lower line must be too low. There are a number of reasons for this, but the following are the most obvious: birds flying into the large $400 \mathrm{kv}$ conductors of the National Grid do not usually cause power failure and hence do not have the high reporting rate of birds striking the smaller conductors ( $240 \mathrm{v}-66 \mathrm{kv}$ ) where power failures do occur (the recent introduction of "auto-reclose" mechanisms, whereby, if the fault is transient, the power supply is automatically resumed after a 2-4 second interruption, will result in more bird strikes going un-noticed in the future). Although engineers are required to report the cause of power failure, they may not look for, or find a ring. Further, many of the dead birds are swiftly dismembered by foxes and so the repair crew may not find the ring, even if they look for it. Many collisions take place over water and the bodies will be swept downstream and neither found by a repair team nor associated with the overhead wires by members of the public.

b) Wire deaths as a measure of swan activity It seemed possible to use the frequency of deaths from collisions with wires to derive a pattern of the flying activity of Mute Swans. Figure 2 shows the proportion of swan deaths resulting from collisions with overhead wires in relation to time of year. There are no very significant differences in this proportion during the period October to May, though there is a small decrease in the proportion dying from flying into wires in mid-winter. The proportion of swans dying from flying accidents is much lower in the period June to September. This is hardly surprising since all birds undergo a complete wing moult, during which they are flightless for a period of about six weeks. The peak time for moult is July. Further, breeding birds stay with their cy gnets from hatching (May-June) to September without flying much during this period. Hence this pattern fits fairly well with what we would expect.

Figure 3 shows the numbers of wire deaths by month for first year birds, plotted against all other reported deaths for the same period. It can be seen that the patterns of mortality from wires and other causes are different. Although both show a marked rise in mortality in September and October, deaths from wires drop thereafter, while deaths from other causes are highest in mid-winter. This is presumably due to the fact that more cygnets die in cold weather in winter than during milder periods (Perrins 1991).

This overall situation masks some variation in the pattern. By analysing only the deaths of birds ringed as cygnets, and hence whose date of birth can be determined, we find that the numbers dying from flying accidents in different months varies with age (Fig. 4). In all cases, the low death-rate from flying accidents during the summer is apparent. However, birds in their first year (Fig. 4a) show higher activity in the autumn and the spring than in mid-winter, the autumn death-rate being particularly high.

Figure $4 \mathrm{~b}$ shows the monthly pattern of flying accidents for birds in their second year of life; in these birds, the autumn peak of accidents is less marked and the spring peak more marked, than in the first-year birds. Birds in their third and fourth years of life (Figs $4 c$ and $4 d$ ) show no signs of a peak in autumn and have the highest numbers of deaths in January and February. Birds in their fifth and sixth years (Fig. 4e) show a spring and an autumn peak with a lower loss in mid-winter. Note that the sample sizes are getting rather small and that the autumn peak arises solely from October losses. Birds in the seventh or later years of life (Fig. 4f) show little sign of an autumn peak, but some signs of elevated mortality due to collision with overhead cables in March and April.

We have also looked at the proportion of deaths due to collisions with overhead wires in relation to age and the results are shown in Figure 5 . There is a highly significant drop in the collision rate; this is most marked between the ages of four and six. There is also sometimes an increase in aerial activity in periods of particularly cold weather; many small waters freeze over and the birds are forced onto larger waters. Movements from still waters such as gravel pits to rivers are noticeable. We have tried to relate the numbers of wire casualties to low temperatures. We did this by using the number of degrees of frost which were recorded in each month at Oxford, a fairly central site, and comparing this measure with the number of wire deaths recorded during that month (for further details of the method see Perrins 1991). However, there was no evidence that more swans fly into wires in periods of extreme cold. One factor that might help them to avoid wires under these conditions is that the ground is often snow-covered and so wires may stand out particularly clearly.

c) The effect of lead poisoning on collision-rate Many swans have died of lead poisoning, from 

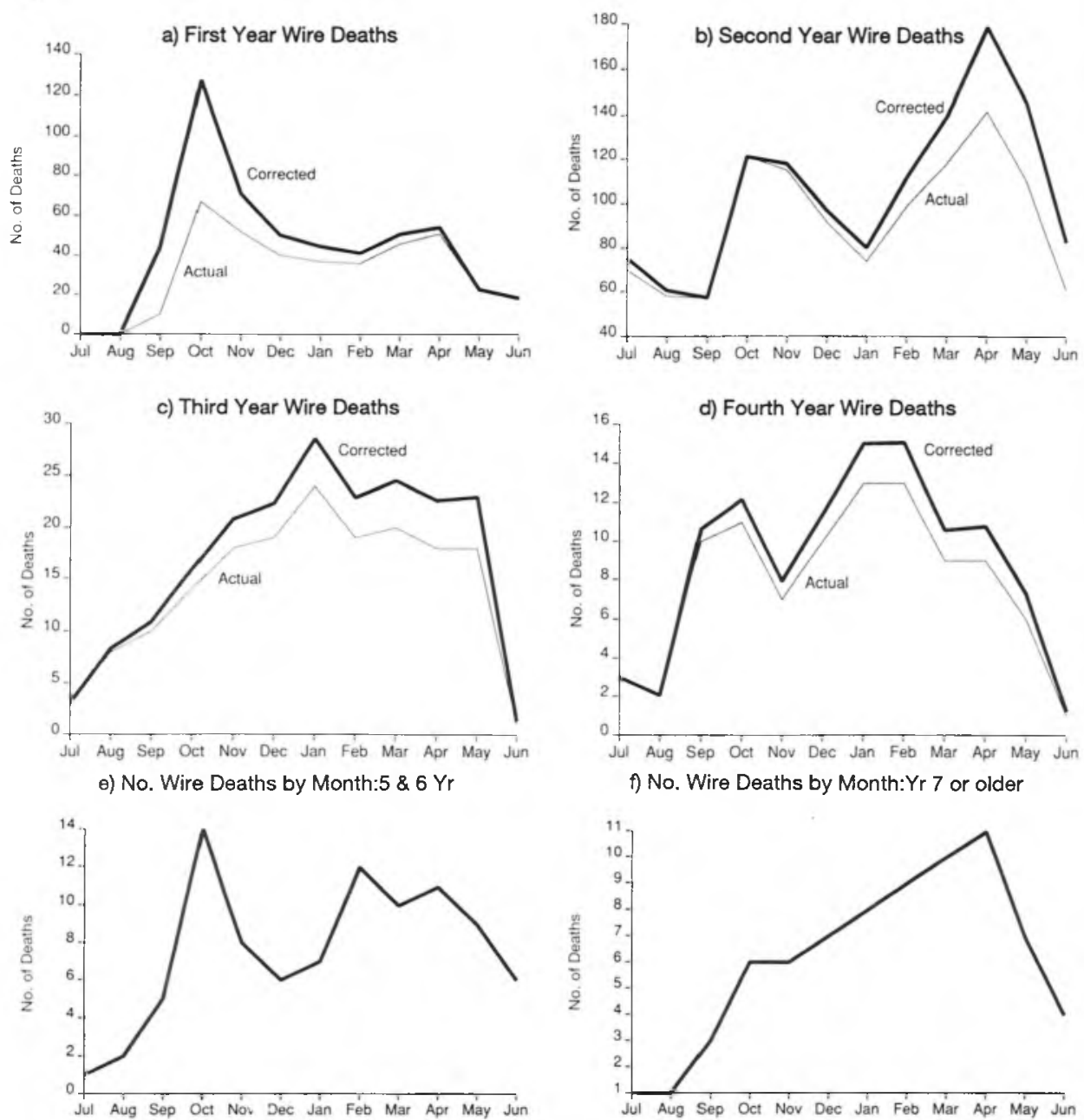

Figure 4. The number of Mute Swans killed by flying into overhead wires in each month. 4a shows the data for birds in their first year, $4 \mathrm{~b}$ is for birds in their second year, $4 \mathrm{c}$ for birds in their third year, $4 \mathrm{~d}$ for birds in their fourth year, $4 \mathrm{e}$ for birds in their fifth and sixth years (combined) and $4 \mathrm{f}$ for birds that were in their seventh or later years. See text for distinction between actual and adjusted numbers.

ingestion of lead weights (Simpson et al. 1979, Birkhead 1982, O'Halloran et al. 1988, Sears 1988). It has been suggested that there might be sub-lethal effects which would cause other problems. In particular, since high lead-levels affect the neuro-muscular system, resulting in motor difficulties, birds with high lead levels might be prone to suffer from flying accidents. In Ireland, O'Halloran et al. (1989) have found, excluding birds which had died of lead poisoning, higher lead levels in the tissues of birds which had collided with wires than in other birds which had not died from this cause and Mathiasson (1986) has reported similar results for swans in west Sweden. Table 1 shows the results for our study area in central England. There is no evidence from these data that birds involved in collisions tend to have elevated lead levels. In fact, the results are in the opposite direction, with birds dying from other causes having significantly higher lead levels than those dying from collisions (though see Discussion).

\section{Discussion}

These analyses show that a significant proportion of the Mute Swans in Britain die from collisions with overhead wires, although it is impossible to give a precise figure. The use of the proportion of birds dying from flying into overhead wires as a measure of flying activity seems reasonable. 


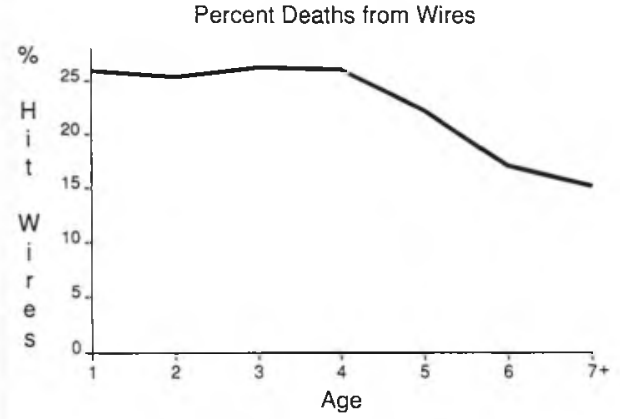

Figure 5. The percentage of reported Mute Swan deaths due to collisions with overhead wires, plotted against age of bird. Numbers show sample sizes.

Such analyses rely on the assumption that flying birds are equally likely to fly into wires at all times of the year. This might not be entirely true since one could imagine that birds are more prone to hit wires under certain conditions (e.g. fog); if this is true, then mid-summer flight would be under-represented. Nevertheless, the overall pattern is much as one would expect.

A lower proportion of breeding adults is killed than of the younger, non-breeding section of the population. This difference could arise from learning. However, the situation does not seem to be quite as simple as that. First, there is no change in the death-rate from collisions with wires during the first four years of life and, second, older birds are more prone to fly into wires in spring than autumn which does not support the suggestion that the process is solely learning. Nevertheless it remains possible that established adults are aware of the positions of overhead wires in their territory, thus leading to a reduction in losses in these age groups.

Some of these patterns fit with what is already known about the movements of Mute Swans. Cygnets start to fly in September and many leave their natal territories in October and November; losses from cables are common at this time. Once the birds have settled in a non-breeding flock, they tend to stay there for at least eighteen months since few birds look for a breeding territory until they are at least two years of age. Birds living in such flocks are not immune to flying accidents, however, since some of the flocks move about, especially moving to safe moulting places in the spring. Once the birds enter their third and fourth years of life they should be starting to look for breeding territories since most birds first attempt to breed at ages of three or four (Birkhead \& Perrins 1985), though once they have settled on a territory, many of them do not move much (Scott 1984). Hence movements and flying accidents in early spring are to be expected. The high mortality in mid-winter is less easily explained unless birds are moving out looking for territories earlier than we expect. All the older age-classes show signs of spring peaks in losses due to cables. The reason for this is not entirely clear. All these birds are of breeding age and we would have expected them to have been settled on their breeding territories by March at the latest and not to have high losses due to wires in April. It is possible that the lag between time of death and subsequent discov-

Table 1. Median lead levels comparing three categories of Mute Swan deaths: lead poisoning, collisions and swans which died from other causes.

\begin{tabular}{|c|c|c|c|c|}
\hline & & \multicolumn{3}{|c|}{ Tissue lead levels (ug/g dry makter) } \\
\hline & & Lead poisoned & Collisions & Other causes \\
\hline \multirow[t]{3}{*}{ Liver } & median & $55.5 * *$ & 2.6 & $4.7^{* \pi}$ \\
\hline & range & $1-404$ & $0.1-15$ & $0.1-45$ \\
\hline & $n$ & 124 & 56 & 145 \\
\hline \multirow[t]{3}{*}{ Kidney } & median & $364 * *$ & 6.1 & $13.6^{* *}$ \\
\hline & range & $27-6560$ & $0.1-66$ & $0.3-93$ \\
\hline & $n$ & 123 & 56 & 143 \\
\hline \multirow[t]{3}{*}{ Bone } & median & $145^{\star \star}$ & 49 & $68.5^{\star}$ \\
\hline & range & $5-2292$ & $1.0-269$ & $1.0-711$ \\
\hline & $n$ & 122 & 54 & 144 \\
\hline
\end{tabular}

Notes: lead poisoned birds were diagnosed on the basis of an elevated kidney lead level (over 100 ug/g dry matter) and other signs of lead poisoning. Six birds had kidncy lead levels over $100 \mathrm{ug} / \mathrm{g}$, but did not die from lead poisoning (one flew into wires, five died from other causes). These six birds have been omitted from all three sets of data in the table, but their inclusion does not affect the results of the statistical analyses.

Mann Whitney U-test ${ }^{\star}=P<0.05,{ }^{\star}=P<0.01$. Lead poisoned birds had significantly more lead in all tissues than birds dying from the other two causes of mortality and those dying from "Other Causes" has significantly more lead in their tissues than those dying from collisions. 
ery is sometimes long enough to account for this anomaly, especially in cases such as this where the number of April casualties is rather small, a larger sample might change the picture. Some such movements may be associated with bereaved birds returning to flocks in search of a new mate.

There is another difference between the birds in their fifth and sixth years and the older ones and this is the peak of losses in October shown by the younger group (Figs $4 \mathrm{e}$ and $\mathrm{f}$ ). The most likely explanation for this is that these are birds which fly off with their brood when the latter start making their first flights; at least some parents do move around at this time with their young. Hence the adult losses are associated with the first year losses at this time (Fig. 3a). However. if this is the explanation, why do we not see it in the older age group? A possible explanation is that there are territories with dangerous overhead cables where the birds have a high risk of collisions and others where this is not the case. Some territories have a high turnover of birds while others do not.

That something of this sort might be involved is apparent from Figure 5 which shows the percentage of deaths due to overhead wires in relation to age. Mortality from this cause drops by almost a half over the period from four to six years of age.

It has been suggested that birds flying into overhead wires may be weakened in some way which reduced their chances of seeing or avoiding the wires. Since it has been known that many birds were dying of lead poisoning and since lead poisoning affects certain neuro-muscular activities (Buck et al. 1976), it has been suggested that many of the birds which flew into wires might have been suffering from sub-lethal effects of lead poisoning (Birkhead 1982). Although such an association between elevated tissue lead levels and flying accidents has been shown by O'Halloran et al. (1989) and Mathiasson (1986), our data do not show such an association. We are not particularly surprised by this; swans which are suffering from lead poisoning may show a marked lowering of condition, especially loss of weight associated with muscle-wasting (Simpson et al. 1979, Birkhead 1982). Hence, except in the very early stages, we might expect them to be unlikely to be in a sufficiently fit condition to attempt take-off which is a very energy-demanding procedure.

Unfortunately, it is difficult to compare average tissue lead values with O'Halloran et al. (1989) and Mathiasson (1986) due to the different units used (wet and dry matter). However, it appears that Mathiasson (1986) recorded considerably lower lead levels in his "healthy" swans than were recorded from any of the three categories in the Thames study. This suggests much lower levels of background contamination in west Sweden which is not surprising given the predominately urban nature of the Thames study area. One reason why the pattern of relative lead levels recorded in the Thames area was opposite to the patterns recorded elsewhere may be due to differences in the geographical distribution of the deaths. The majority (around $85 \%$ ) of the collision deaths occurred in the rural areas of the Upper Thames and tributaries west of Oxford whilst the deaths from other causes were more common throughout the urban areas of the Thames valley, where the background levels of lead are higher (Sears 1988). Hence we may not be, strictly, comparing like with like.

We are grateful to the British Trust for Ornithology and the Swan Study Group for permission to computerise all the swan ringing data and to analyse the ringing recoveries in this way. Dr R.H. McCleery provided much computing help and Dr D.K. Scott kindly commented on the manuscript.

\section{References}

Birkhead, M.E. 1982. Causes of mortality in the Mute Swan Cygnus olor on the River Thames. J. Zool. Lond. 198:15-25.

Birkhead, M.E. \& Perrins, C.M. 1986. The Mute Swan. Christopher Helm.

Buck, W.B., Osweiler, G.D. \& van Gelder, G.A. 1976. Clinical and diagnostic veterinary toxicology. 2nd ed. pp. 319-332. Kendall/Hunt, Iowa.

O'Halloran, J., Myers, A.A. \& Duggan, P.F. 1988. Lead poisoning in swans and sources of contamination in Ireland. J. Zool. Lond. 216:211-223.

O'Halloran, J., Myers, A.A. \& Dugan, P.F. 1989. Some sub-lethal effects of lead on Mute Swans Cygnus olor. J. Zool. Lond. 218:627-632.

Mathiasson, S. 1986. Lead in tissues and gizzards of mute swans Cygnus olor from the Swedish 
west coast, with remarks on other heavy metals and possible additive and synergetic effects. Var Fagelvarld, Suppl. 11:111-126.

Perrins, C.M. 1991. Survival rates of young Mute Swans Cygnus olor. In: J. Sears \& P.J. Bacon (Eds.) Proc. 3rd Int. Swan Symposium, Oxford 1989. Wildfowl Special Supplement No. 1, pp. 95-103.

Scott, D.K. 1984. Winter territoriality of Mute Swans Cygnus olor. Ibis 126:168-176.

Sears, J. 1988. Regional and seasonal variations in the incidence of lead poisoning in the Mute Swan Cygnus olor in relation to the distribution of lead and lead weights in the Thames area, England. Biol. Cons. 46:115-134.

Sears, J. 1989. A review of lead poisoning among the River Thames Mute Swan Cygnus olor population. Wildfowl 40:151-152.

Simpson, V.R., Hunt, A.E. \& French, M.C. 1979. Chronic lead poisoning in a herd of Mute Swans. Env. Pollut. 18:187-202.

C.M. Perrins and J. Sears, Edward Grey Institute of Field Ornithology, Dept. of Zoology, South Parks Road, Oxford.

(J. Sears is now at R.S.P.B., The Lodge, Sandy, Bedfordshire, SG19 2DL). 